\title{
Assessment of antihyperglycemic and antihyperlipidemic activity of common ayurvedic formulation in alloxan- induced diabetic rabbits.
}

\author{
Zaman.Z.A ${ }^{1}$, Singh.G.P2 \\ ${ }^{1}$ (Assistant professor,Dept of Pharmacology,Shri Krishna Medical College,Muzaffarpur,India) \\ ${ }_{2}^{2}$ (Professor,Dept of Pharmacology,Shri Krishna Medical College, Muzaffarpur,India)
}

\begin{abstract}
Objective: The present study was planned to evaluate the efficacy of four different ayurvedic formulation for their antihyperglycemic and antihyperlipidemic effect in alloxan induced diabetic rabbits Materials and Methods: Four different ayurvedic formulation $(F 1, F 2, F 3, F 4))$ were administered in different group of alloxan induced diabetic rabbits.Their efficacy, onset and duration of action as antihyperglycemic agents were studied. Their antihyperlipidemic action were also compared.

Results: Out of four formulation $(F 1, F 2, F 3, F 4)$ studied formulation-F2, showed extremely significant antihyperglycemic activity for satisfactory duration and also showed a significant activity as an antihyperlipidemic agent compared to other three and Tolbutamide.

Conclusion: A number of polyherbal formulation are widely marketed claiming to be very effective in diabetes and other associated disease. But, this study indicates that, though there are numerous traditional plants reported to have hypoglycemic properties, many of them proved to be not very effective in lowering blood glucose levels in severe diabetes.
\end{abstract}

Keywords: Antihyperglycemic, antihyperlipidemic, ayurvedic formulation, diabetes, Tolbutamide

\section{Introduction}

Diabetes mellitus is a known metabolic disorder of varied etiology characterized by chronic hyperglycemia due to relative deficiency of insulin or its resistance. Diabetes is associated with disturbance of carbohydrate, fat and protein metabolism [1).Herbal formulation have been used by the majority of Indians since ancient times. In recent years, there has been an increased inclination towards the herbal formulation due to the trend towards the natural sources and healthy life style. Moreover, the complexity, side effects costly treatment associated with allopathic medicine have caused both the health care practitioners and majority of world populations to turn towards the alternative therapies, more likely towards the herbal medicines, since these systems are believed to be free from side-effects and affordable. Ayurvedic formulation are used to treat a wide variety of disease including diabetes mellitus. The metabolism of glucose, protein and lipids is abnormal in diabetes due to insulin secretion defect, leading to various metabolic disorder [2] and complications [3] Most of the hypoglycemic agents and hypolipidemics used in allopathic practice to treat diabetes mellitus and hyperlipidemia are reported to have side effects in long term use [4]. Hence there is need to search for effective and safe drugs for these ailments. Pharmaceutical research across the world shows that, natural products are potential sources of novel molecules for drug developments [5] . The documented reports authenticate that, though there are numerous traditional plants reported to have hypoglycemic properties, many of them proved to be not very effective in lowering blood glucose levels in severe diabetes [6]. Hence there is need to explore herbal medicine in the context of modern science and validate accordingly. In the last decade, WHO had passed many resolutions vis-à-vis improving the quality and efficacy of plant drugs .Documented reports suggest the presence of hypoglycemic, antihyperlipidemic and other activities of plant's material used in the 4 marketed herbal formulation F1,F2,F3,F4, $[7,8,9,10,11,12,13,14,15,16,17,18]$. Hence, in the present study, the efficacy of the four marketed ayurvedic antidiabetic formulation for their antihyperglycemic and antihyperlipidemic activities in alloxan-induced diabetic albino rabbits was studied. 


\section{Material and Methods}

All the four formulation used in the study were purchased from retail chemists and composition of each formulation as it appeared in the label as follows.

\section{FORMULATION-F1}

Cassia Auriculata (200mg), Eugenia Jambolana(200mg), Mamordica Charantia(200mg), Gymnema Sylvestra(100mg), Mangifera Indica(100mg), Tinospora Cardifolia(100), Aegle Marmelos(100mg), Pterocarpus Marsupium(100mg), Trigonilla Foenum Graeceum(100mg), Melia Azadirachta(100mg), Curcuma long(Haldi)(100mg), Cascaria Esculenta(50mg) Withenia

\section{FORMULATION-F2}

Somnifera $(50 \mathrm{mg})$

Curcuma Longa(100), Eugenia Jambolana(50mg), Swertia Chirata(50), Shilajit Shudha(25mg), Trivang Bhasma(25mg), Cassia Auriculata(100mg), Emblica Officinalis(100mg), Enicostemma Littorale(50mg), Gymnema Sylvestra(50mg), Pterocarpus Marsupium(50mg), Tinospora Cordifolia(50mg) and Melia Azadirachta(50mg).

\section{FORMULATION-F3}

Enicostemma Littorale(33.33mg), Phylanthus Amarus(33.33mg), Eugenia Jambolana(33.33mg), Melia Azadirachta(33.33mg), Terminalia Arjuna(33.33mg), Aegle Marmelos(33.33mg), and Asphalatum(30mg).

\section{FORMULATION-F4}

Gymnema Sylvestre(75), Momordica Charantia(81mg), Cassia Auriculata(63mg), Syzgium Cumini(96mg), Phyllanthus emblica(48mg), Melia Azadirachta(30mg), Trigonella Foenum Graecum(15mg), Coccinia Indica(93mg), Tinospora Cordifolia(63mg), Javakhar(12mg).

Experimental animals- The study protocol was duly approved by the institutional animal ethical committee and was conducted in accordance with the National Institute of Health(NIH) guidelines, at an institution, approved by the Committee for the Purpose of Control and Supervision of Experiments in Animal(CPCSEA). Albino rabbits of either sex weighing between 1.5 to $2 \mathrm{~kg}$ were randomly selected. These animals were caged individually in similar environmental condition and were categorized into six groups $(n=5)$.

Induction of Diabetes- The rabbits were injected with freshly prepared alloxan monohydrate $150 \mathrm{mg} / \mathrm{kg}$ through subcutaneous route. Blood glucose levels were estimated after $24 \mathrm{hr}$ and $48 \mathrm{hr}$ to confirm development of diabetes. The diabetic rabbits exhibiting persistent blood sugar level in the range of 250-300 $\mathrm{mg} / \mathrm{dl}$ were selected to determine efficacy of the formulation. Alloxan was used since it produce hyperglycemia ,hypercholesterolemia and elevated lipid peroxidases levels [19] which is the appropriate model for the present study.

Experimental procedure- All the animals were fasted for 18 hours and given water ad libitum. After $18 \mathrm{hr}$ of fasting "Zero" hour blood samples were collected from all the animals of each group and the drug was administered orally to each group as follows. The dose of different formulation was selected by extrapolating the human dose to the animal dose as described by Laurence and Bacharach [20] and administered orally by suspending individually in $20 \%$ w $/ \mathrm{v}$ acacia suspension in distilled water. GROUP-1 $2 \%$ Acacia suspension(Control) GROUP-2 Formulation- $\quad$ F1 $\quad(\quad 130 \mathrm{mg} / 1.5 \mathrm{~kg})$ GROUP-3 Formulation- $\quad$ F2 $\quad(\quad 100 \mathrm{mg} / 1.5 \mathrm{~kg})$ $\begin{array}{lllll}\text { GROUP-4 Formulation- } & \mathrm{F} 3 & (94 \mathrm{mg} / & 1.5 \mathrm{~kg})\end{array}$ $\begin{array}{lllll}\text { GROUP-5 Formulation- } & \text { F4 } & 104 / & 1.5 \mathrm{~kg})\end{array}$ GROUP-6 Tolbutamide (40 mg/kg), (Positive Control)

Serum analysis- The blood samples were collected from the marginal ear vein at $0,4,6,8,12$, and 24 $\mathrm{hr}$ and blood glucose levels were estimated by Glucometer(Acu-Chek, Johnson-Johnson). The serum triglyceride [21], high density lipoprotein [22], and total cholesterol [23], levels of all the groups were estimated and compared with the control group. The antihyperglycemic activity of all the four formulation at the time interval ' $t$ ' was calculated as the percentage of blood glucose reduction at that times with respect to basal blood glucose level. The antiglycemic activity results are outlined in Table-1 and the antihyperlipidemic activity is 
graphically depicted in Figure-1,2,3. Statistical Analysis- The values are reported as mean \pm SEM. The data was analysed by one-way analysis of variance(ANOVA), followed by Tukey-Kramer multiple comparisons, $p$ value lower than 0.05 were considered statistically significant.

\section{Results}

From the results outlined in the Table-1 depicted graphically in the figures 1,2,3 the following can be deduced. Out of four formulation F1,F2,F3,F4, studied, formulation F1,F3 and F4 exhibited the onset of action around $12 \mathrm{hr}$ after administration, whereas the formulation $\mathrm{F} 2$ showed an earlier onset of action compared to other three, around $8^{\text {th }} \mathrm{hr}$. The formulation F1 and F4 exhibited the peak antihyperglycemic effect at $24^{\text {th }} \mathrm{hr}$ by reducing the blood sugar level by $50.22 \pm 2.62 \%$ and $49.23 \pm 1.21 \%$ respectively, which is less than that of tolbutamide. But the formulation F3 the peak effect a little later than the other two by reducing blood sugar level to $55.86 \pm 3.15 \%$ at $30^{\text {th }} \mathrm{hr}$, which is almost comparable with that of tolbutamide $(56.12 \pm 1.06 \%)$ at the $4^{\text {th }} \mathrm{hr}$. Out of the four formulations studied, formulation F2 exhibited the peak effect at $24^{\text {th }} \mathrm{hr}$ by reducing the blood sugar level by $68.21 \pm 2.11 \%$, which is extremely significant and higher than that exhibited by the tolbutamide. The duration of action of the formulation F1 and F4 were between 18-24 hr, whereas that of formulation F2 was more than 24hr. Similarly out of four formulation F4' exhibited very significant reducing effect on all serum lipids except HDL-cholesterol. The formulation F' ${ }^{\prime}$ showed the significant effect only on triglycerides and VLDL-cholesterol. On the other hand, formulation F2' showed the very significant effect on reducing total cholesterol and significant effect on triglycerides, LDL-cholesterol, VLDL-cholesterol and HDL-cholesterol. The formulaion F3' exhibited no satisfactory reduction of none of the lipids studied

Table 1. Antihyperglycemic effect of four Ayurvedic formulation in diabetic rabbits Percent blood glucose reduction with different formulation and Tobutamide

\begin{tabular}{|l|l|l|l|l|l|}
\hline $\begin{array}{l}\text { Time in } \\
\text { hours }\end{array}$ & Formulation-F1 & Formulation-F2 & Formulation-F3 & Formulation-F4 & $\begin{array}{l}\text { Tolbutamide } \\
(40 \mathrm{mg} / \mathrm{kg} \mathrm{p} . \mathrm{o})\end{array}$ \\
\hline 0 & 0 & 0 & 0 & 0 & 0 \\
\hline 2 & $4.65 \pm 0.86$ & $6.46 \pm 0.34$ & $3.82 \pm 1.52$ & $5.21 \pm 1.36$ & $41.79 \pm 2.18$ \\
\hline 4 & $11.52 \pm 0.10$ & $13.08 \pm 0.54$ & $6.11 \pm 2.06$ & $9.12 \pm 2.11$ & $56.12 \pm 1.06$ \\
\hline 6 & $17.58 \pm 2.04$ & $18.46 \pm 0.55$ & $8.25 \pm 1.72$ & $11.23 \pm 2.05$ & $52.24 \pm 0.68$ \\
\hline 8 & $23.45 \pm 0.24$ & $28.54 \pm 0.64$ & $12.16 \pm 1.96$ & $13.12 \pm 1.89$ & $41.22 \pm 1.66$ \\
\hline 12 & $27.94 \pm 2.12$ & $45.12 \pm 1.87$ & $30.15 \pm 1.66$ & $28.67 \pm 1.02$ & $27.21 \pm 2.05$ \\
\hline 24 & $50.22 \pm 2.62$ & $68.21 \pm 2.11$ & $44.14 \pm 2.35$ & $49.23 \pm 1.21$ & $15.07 \pm 1.66$ \\
\hline 30 & $37.86 \pm 2.06$ & $65.12 \pm 0.62$ & $55.86 \pm 3.15$ & $40.08 \pm 1.06$ & $14.06 \pm 1.55$ \\
\hline
\end{tabular}

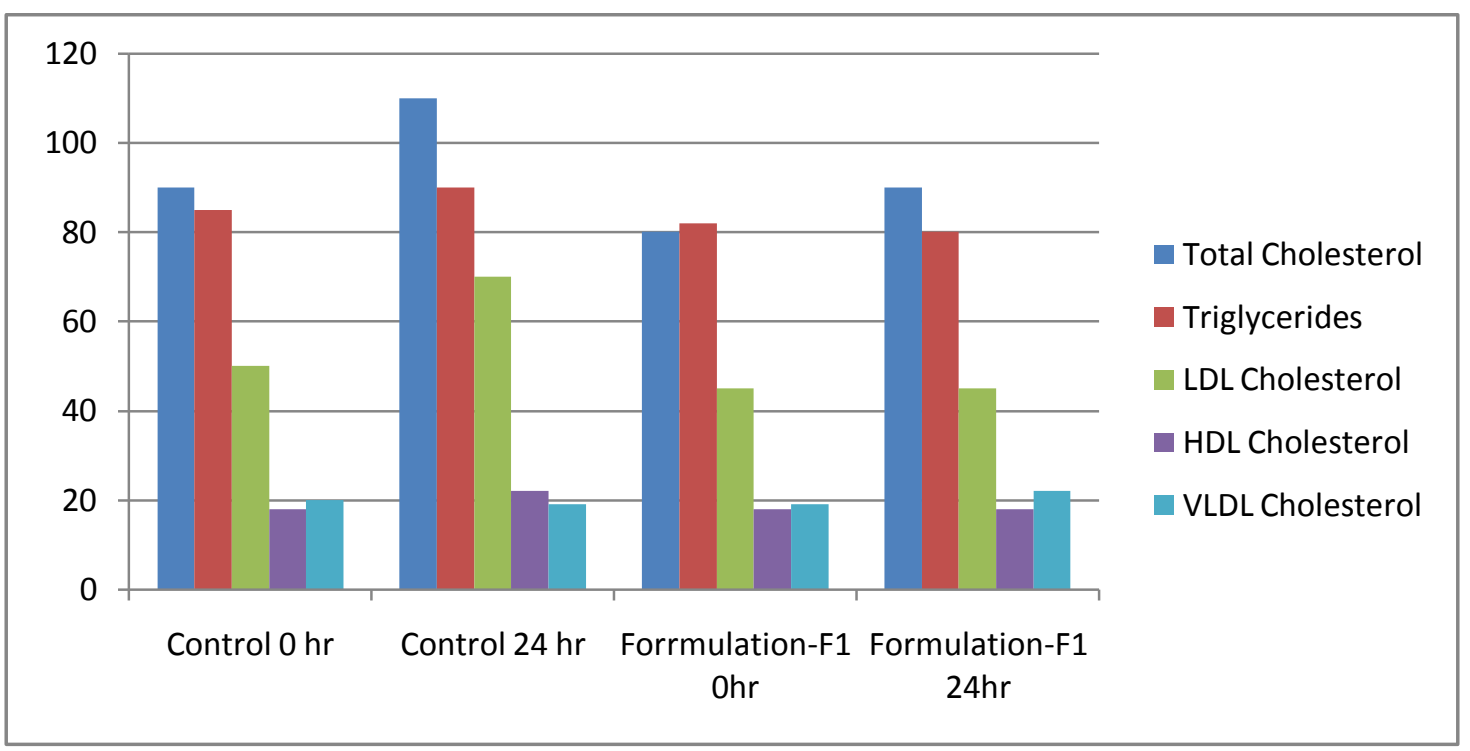


Figures-1,2,3 Change in serum lipid levels (mg\%) with Ayurvedic antidiabetic formulation in diabetic rabbits
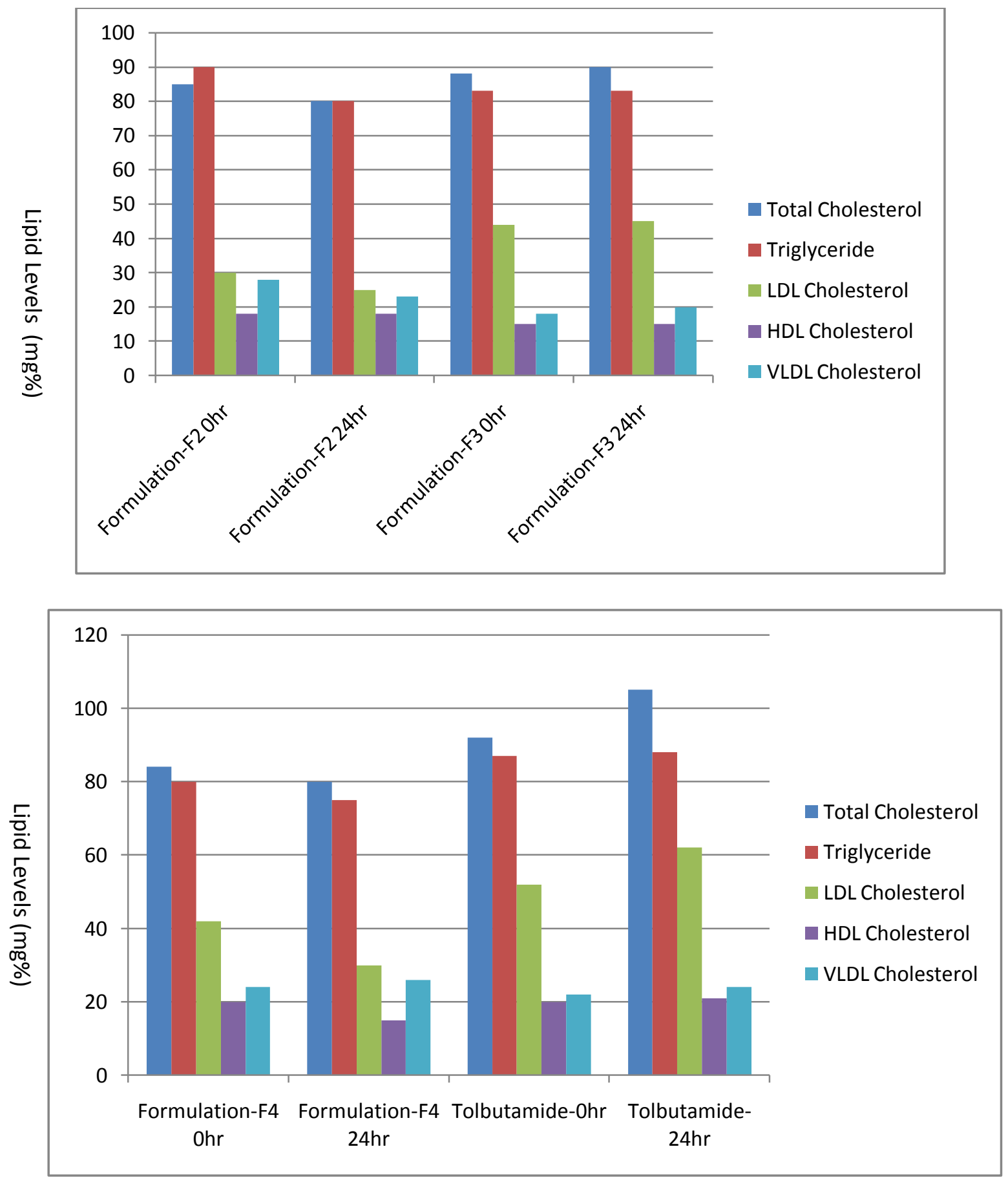

IV. Discussion

Diabetes mellitus is world's largest growing metabolic disease and as the knowledge on the heterogenecity of this disorder is advanced, the need for more appropriate therapy increases [24].The incidence of atherosclerosis is very high in diabetics [25] .An ideal treatment for diabetes would be a drug that are not only controls the glycemic levels but also prevents the development of arteriosclerosis and other complication of diabetes [26].Diabetes is associated with hyperlipidemia [27]. A reduction in serum lipids, particularly of the LDL and VLDL fraction and triglycerides, should be considered as being beneficial for the long term prognosis of these patients [28]. The increase in HDL may slow down the atherosclotic process [29]. In allopathic practice 
no drug is available which reduce both blood sugar and serum lipids in diabetes associated with hyperlipidemia. Muti-drug therapy used in the treatment of these ailments may lead to side effects and adverse drug interactions in the long run. On the other hand, there are several polyherbal formulation in the ayurvedic system which are very useful in the management of these two ailments and are believed to be free from side effects. The concept of efficacy in phytotherapy is based on the mixture of substance contained in the medicinal plants and the polyherbal formulation composed of more than one herbal ingredient have specific time proven therapeutic values [30]. In the present study, among the four formulation, formulation F2 showed extremely significant antihyperglycemic effect. It showed the onset of action relatively early ( $8 \mathrm{hr})$ and duration of action was for a satisfactory period(>24hrs), whereas the formulation F1 showed a weak antihyperglycemic effect, compared to formulation F3. The formulation F1, F3 and F4 showed the onset of action around 12 hours and duration of action for 18-24 hours, which is less than that of F2. Formulation F4, exhibited a weak antihperglycemic effect compared to the other three. Based on their antihyperglycemic efficacy and the duration of action the four formulation can be ranked in the order of : F2 $>F 3>F 1>F 4$. Similarly, the formulation F4 and F2 exhibited highly significant antihyperlipidemic activity on serum lipid profiles compared to others. Between formulation F1 and F3 formulation F1 showed significant effect only on triglyceride and VLDL-cholesterol. But their effect on total cholesterol and LDL-cholesterol was not quite significant . Depending upon their antihyperlipidemic efficacy the formulation are arranged in the following order: $\mathrm{F} 4>\mathrm{F} 2>\mathrm{F} 1>\mathrm{F} 3$.

\section{Conclusion-}

The present study showed that marketed ayurvedic antidiabetic formulations have different antihyperglycemic and antihyperlipidemic activities. Formulation-F2 was found to be superior. It exhibited optimum antihyperglycemic and antihyperlipemic activities compared to the control and others. The result of the study provide a ready reference for the selection of an appropriate formulation in the clinical practice and hence effective rational therapy. It is very difficult to point out an ingredient responsible for these favourable responses. According to ayurvedic texts, substances are used in combination in order to get the enhanced desired action and to eliminate unwanted side effects.

[1] Sheriff,D.S(1990), Med.Biochem, $4^{\text {th }}$ edn.

\section{Reference}

[2] Punitha,R.Vasudevan,K. and Manoharan,S(2006).Effect of Pongamia Pinnata flowers on blood glucose and oxidative stress in alloxan induced diabetic rat. Indian.J.Pharmacol;38(1):62-63 Saudek,C.D.and Eder,H.A.1979.Lipid metabolism in diabetes mellitus.Am.J.Med; 66:843-8524.

[3] Khan,C.R. and Schecter,Y.(1991). Insulin ,Oral hypoglycemic agents and the pharmacology of endocrine pancreas,in(Goodman and Gillmans, The Pharmaceutical Basis of Therapeutics $8^{\text {th }}$ ed) (Pergaman Press,New York)p.1463.

[4] Marles,R.J.and Franworth,N.R.(1995).Plants to patients: an ethnomedical approach.Phytomedicine 2:137.

[5] Nagarajan,S.Jain,H.C. and Anulakh,G.S.(1987) Indigenous plants used in the control of diabetes(Publication and Information Directorate,New Delhi), C.S.I.R.P 599

[6] Aiman R (1970) Recent research in indigenous antidiabetic medicinal plants: An overall assessment. Indian J.Physiol.Pharmacol.14:65-74 8.Mukherjee,B. and Mukherjee,S.K..(1987).Blood sugar lowering activity of Swertia Chirata(Buch-Ham)extract.Int. J.Crude Drug.Res.25:97-102.

[7] Thompson,G.R.(1990).Lipids and Cardiovascular disease. British Medical Bulletin.46:986.

[8] Dubey,G.P. Agrawal A and Sing A(1993).Evaluation of D-400,an indigenous herbal preparation in diabetes mellitus, Indian.J.Int.Med.3:183-186.

[9] Ponnachan,P.T.C. Paulose,C.S.and Pannikar,K.R. (1993).Effectof Leaf extract of Aegles marmelose in diabetic rats.Indian .J. Exp. Biol.31:345-347.

[10] Bhattachary,S.K.(1995).Activity of Shilajit on alloxan induced hyperglycemia in rats. Fitoterapia. 66:328-332.

[11] Dwivedi, S.(1996). Putative use of Indian cardiovascular friendly plants in preventive cardiology. Annal of National Academy of Medical Science(India).32:159-175.

[12] Babu,P.S. and Srinivasan,S.K.(1997). Hypolipidemic action of Curucumin,the active principle of turmeric(Curcuma Longa) in streptozotocin induced diabetic rats.Mol.Cell. Biochem. 166;169-175.

[13] Shaila,H.P. Udupa,S.C. and Udupa,A.L.(1997).Hypolipidemic effect of Terminale arjuna in cholesterol fed rabbits. Fitoterapia 68:405-409.

[14] Chattopadhyay,R.R.(1998).Possible mechanism of antihyperglycemic activity of Gymnema sylvestre leaf extract. Part1,Gen.Pharmacol. 31:495-496.

[15] Goyal,R.K. Upadhyay,V.M.. and Murali,B.(1999).Antidiabetic activity of Enicostemma Littorale on diabetic rats. Ind. J. Pharmacol. 31: 57-58.

[16] Srinivasan,B.P.(1999).Pharmacological evaluation of Azadirachta Indica. Ind. J. Pharmacol. 31:56.

[17] Cross,C.E. Halliwell,B. Borish,E.T. Prayor,W.A. and Ames.B.N (1992). Oxygen radicals and human disease. Ann.Intern.Med.107:526-545.

[18] Laurence,D.R and Bacharach,A.L.(1993).Evaluation of Drug activities and Pharmacometrics, Academic Press London and New York. 1:p.160-161. 
[19] Tiffany, T.O. Morton,J.M. Hall,E.M. and Garret,A.S.(1974). Clinical evaluation of kinetic enzymatic fixed time and integral analysis of serum triglycerides. Clin.Chem.20:476-481.

[20] Burstein, N. Scholnick,H.R . and Morfin, R. (1970). Determination of HDL-cholesterol phosphotungestic mangnesium method. In : Varly,H. Gowenlock,A.H. and Bell,M. editors(1980). Practical Clinical Biochemistry 1:665-666.

[21] Allian,C.C. Poon,L.S. Chan,C.S. Richmond,W. and Fu,P.C.(1974).Enzymatic determination of total serum cholesterol, Clin Chem.20:p470

[22] Bailey,C.J. and C.Day,1989.Traditional plant medicines as treatment of diabetes. Diab.Care,12:553-564

[23] Kennel,W.B. and Mc Gee,D.L.(1979). Diabetes and cardiovascular risk factors,the Framingham study circulation. 59:8

[24] Haliwell,B. and J.M.Gutteridge,1985.Free radicals in Biology and Medicine. $2^{\text {nd }}$ Edn,Clarendon Press,Oxford.

[25] De-Sereday,M.S;C.Gonzalez;D.Giorgini,L;De-Loredo.J.BraguinskiandC.Cobenas,2004.Prevalenceof diabetes,obesity,hypertension and hyperlipidemia in the central area of Argentina.Diab.Metab;30:335-339.

[26] Chattopadhay,R.F.and M.Bandyopadhay,2005.Effect of Azadirachta indica leaf extract on serum lipid profile changes in normal and sreptozotocin induced diabetic rats.Afr.J.Biomed.Res;8:101-104

[27] Nofer,J.R.Kherel,b.Fobker,M.Levkau,B.Assmann,G. andEchardstein,A.V;2002. HDL and arteriosclerosis:Beyond reverse cholesterol transport,Atherosclerosis, 161:1-16.

[28] Latha,v. Rajesh,M G. and Latha,M.S. (1993).Hepato-protective effect of an ayurvedic medicine.Indian Drug 36:p470 